\title{
A RELAÇÃO TRABALHO-EDUCAÇÃO NO PENSAMENTO DE MARX: UM ESTUDO DOS MANUSCRITOS ECONÔMICO-FILOSÓFICOS (1844)
}

\author{
José Salvador de Almeida ${ }^{1}$ \\ Eduardo Ferreira Chagas ${ }^{2}$
}

\begin{abstract}
Resumo:
Este artigo objetiva demonstrar e explicitar a relação entre trabalho-educação no pensamento de Marx, a partir de um estudo dos Manuscritos econômico-filosóficos (1844), especificamente, do manuscrito intitulado, a saber: Trabalho Estranhado e Propriedade Privada. Neste trabalho, apresentamos, inicialmente, o debate de Marx com a economia nacional e, na sequência, a teoria sobre o estranhamento na essência do trabalho [trabalho estranhado] e, por fim, a relação trabalho-educação para este pensador materialista. Durante o desenvolvimento da referida pesquisa, adotamos como procedimento metodológico o método dialético-crítico-reflexivo, pois tal método, no nosso entendimento, permite uma melhor compreensão dos escritos de Marx. Ao final da pesquisa, evidenciamos que existe uma relação íntima entre trabalho-educação no pensamento de Marx, pois a educação deve proporcionar ao homem (trabalhador) uma relação imediata e de reconhecimento entre o trabalho (atividade vital consciente e livre) e a produção, isto é, entre o trabalhador e os objetos da produção. No capitalismo, tal relação, portanto, se apresenta como uma relação hostil e estranha, pois o trabalhador não se reconhece no produto do seu próprio trabalho, uma vez que este trabalho se apresenta como trabalho estranhado.
\end{abstract}

Palavras-chaves: Relação trabalho-educação. Marx. Trabalho estranhado. Homem. Capitalismo.

\section{THE RELATIONSHIP BETWEEN LABOR AND EDUCATION IN MARX'S THOUGHT: A STUDY FROM HIS ECONOMIC-PHILOSOPHICAL MANUSCRITPS (1844)}

\begin{abstract}
:
This article aims to demonstrate the relationship between labor and education in Marx's thought, from a study of his Economic and Philosophical Manuscripts (1844), specifically, the one entitled: Estranged Labor and Private Propriety. In This work, we present, initially, Marx's debate with national economy and, consequently, his estrangement's theory in the essence of labor [estranged labor] and, ultimately, the laboreducation relationship of this materialist thinker. During the development of this research, we have adopted as methodological procedure the reflexive-critic-dialectic method as a result of understanding that it allows us to better comprehend his manuscripts. At the end of this research, we have demonstrated that exists a profound relationship between labor and education in Marx's thought because education ought to make it possible for man (worker) a direct relationship of recognition between labor (a vital, conscient and free activity) and production or, in other words, between workers and their production. In the capitalist society, such relationship, although, is presented as an estranged and hostile one, once the workers do not recognize themselves in their own production.
\end{abstract}

Keywords: Labor-education relationship. Estranged Labor. Man. Capitalism. Marx.

1 Mestrando em Educação pela Universidade Federal do Ceará (UFC). E-mail: salvadoralmeida002@gmail.com.

2 Doutor em Filosofia pela Universidade Alemã de Kassel; Professor de Graduação e Pós-Graduação do Curso de Filosofia da Universidade Federal do Ceará (UFC); Colaborador do Programa de PósGraduação da Faculdade de Educação (FACED) da UFC e Colaborador do Programa de Pós-Graduação do Mestrado Acadêmico em Filosofia da Universidade Estadual do Ceará (UECE). Bolsista do CNPQ. E-mail: ef.chagas@uol.com.br. 


\section{INTRODUÇÃO}

Ao iniciar a escrita do manuscrito, a saber: Trabalho estranhado $e$ propriedade privada, localizado na obra Manuscritos econômico-filosóficos (1844) ${ }^{3}$, Marx, em seu processo de análise das categorias, leis e conceitos da economia nacional ${ }^{4}$, considera a própria linguagem da economia nacional e constata que quando se trata da realidade material, concreta, tais categorias, leis e conceitos não encontram uma sintonia, isto é, que a realidade da vida humana discorre da teoria apresentada por essa ciência, pois segundo Marx (2010), a partir da própria linguagem da economia nacional, verificase que o trabalhador baixa a condição de mercadoria e à da mais miserável mercadoria, que a miséria do trabalhador se apresenta na vida real, concreta e material em oposição à grandeza da sua produção e que o resultado é que, no final das contas, toda a sociedade decompõe-se em duas classes distintas, a classe dos proprietários e dos trabalhadores sem propriedade.

Pois, segundo Marx,

A economia nacional parte do fato dado e acabado da propriedade privada. Não explica o mesmo. Ela percebe o processo material da propriedade privada, que passa, na realidade (Wirklichkeit), por fórmulas gerais, abstratas, que passam a valer como leis para ela. Não concebe (begreift) estas leis, isto é, não mostra

3 Afirma Sobral que: "Os Manuscritos escritos por Marx em 1844 partem de uma dupla motivação: uma iniciativa de compreender a economia política comparada à filosofia; e uma tentativa de dar orientação a um movimento revolucionário crescente na Europa. A primeira permitiu a Marx estabelecer uma visão coordenada entre os dois campos. A segunda, um desdobramento da anterior, não se caracterizou, pois, esta obra permaneceu sem ser publicada. [...].” (SOBRAL, 2005, p. 13).

4 Segundo Jesus Ranieri, na nota de tradução n 2, dos Manuscritos econômico-filosóficos, "A opção por "economia nacional", em vez de "economia política" é do próprio Marx. Economistas burgueses ingleses e franceses utilizavam, correntemente, political economy e économie politique, mas aos alemães era mais próximo o termo Nationalökonomie. O próprio Marx teria pronunciado, também nos Anais franco-alemães, quando da caracterização da diversidade e de desenvolvimentos das diferentes cidades francesas e inglesas, comparada às alemãs, algo a respeito da oposição entre economia política e economia nacional. Somente mais tarde ele irá converter, nos seus escritos, o conceito de "economia nacional" para "economia política". Importa salientar igualmente que "economia nacional" diz respeito, dependendo do contexto, tanto ao sistema econômico quanto às suas teorizações." (MARX, 2010, p. 19).

\begin{tabular}{|l|l|l|l|l|}
\hline Q Povista Dialectus & Ano 8 & n. 14 & Janeiro - Julho 2019 & p. 278 - 294 \\
\hline
\end{tabular}


como têm origem na essência da propriedade privada. [...]. (MARX, 2010, p. 79).

Diante de tal acusação, convicto de suas palavras, Marx percebe e afirma que a economia nacional não apresenta nenhuma explicação que encontre sua verdade na vida real, ou seja, não mostra a origem dessas leis assentadas na realidade objetiva, material.

A economia nacional, ciência fundamentadora do capitalismo, não apresenta, conforme Marx, esclarecimentos a respeito do fundamento da divisão entre trabalho e capital, entre capital e terra. Quando, por exemplo, fala da concorrência, apresenta sua explicação a partir de circunstâncias exteriores. Pergunta Marx: "Até que ponto estas circunstâncias exteriores, aparentemente casuais, são apenas a expressão de um desenvolvimento necessário?”. (MARX, 2010, p. 79).

Ainda, de acordo com Marx, a troca aparece para a economia nacional como um fato meramente acidental. Assim, Marx (2010) afirma que as únicas rodas que o economista nacional põe em movimento são a ganância e a guerra entre os gananciosos, a concorrência.

Uma vez que a economia nacional, no entendimento de Marx, não explica por não entender a conexão do movimento, ela colocou em oposição à doutrina da concorrência à doutrina do monopólio, a doutrina da liberdade industrial à doutrina da corporação, a doutrina da divisão da posse da terra à doutrina da grande propriedade fundiária, pois concorrência, liberdade industrial, divisão da posse da terra eram concebidas apenas como consequências acidentais, deliberadas, violentas e não como consequências necessárias, naturais do monopólio, da corporação e da propriedade feudal.

Após constatar, no primeiro momento, a impotência da economia nacional, no tocante a elaboração de suas próprias teorias e leis para a explicação da realidade, Marx aprofunda seu processo de análise, agora, no segundo momento, em que busca entender o motivo da interconexão essencial entre a propriedade privada, a ganância, a separação de trabalho, capital e propriedade da terra, de troca e concorrência, de valor e desvalorização do homem, de monopólio e concorrência, etc., de todo esse estranhamento com o sistema do dinheiro.

Na busca pelo entendimento desta explicação, Marx chama a atenção para que

\begin{tabular}{|l|l|l|l|l|}
\hline Govista Dialectus & Ano 8 & n. 14 & Janeiro - Julho 2019 & p. $278-294$ \\
\hline
\end{tabular}


Não nos desloquemos, como [faz] o economista nacional quando quer esclarecer [algo], a um estado primitivo imaginário. Um tal estado primitivo nada explica. Ele simplesmente empurra a questão para uma região nebulosa, cinzenta. Supõe na forma do fato (Talsache), do acontecimento, aquilo que deve deduzir, notadamente a relação necessária entre duas coisas, por exemplo entre a divisão do trabalho e troca. Assim o teólogo explica a origem do mal pelo pecado original (Sündenfall), isto é, supõe como um fato dado e acabado, na forma da história, o que deve explicar. (MARX, 2010, p. 80).

E continua afirmando que "Nós partimos de um fato nacional-econômico, presente". (MARX, 2010, p. 80).

O trabalhador se torna tanto mais pobre quanto mais riqueza produz, quanto mais a sua produção aumenta em poder e extensão. O trabalhador se torna uma mercadoria tão mais barata quanto mais mercadorias cria. Com a valorização do mundo das coisas (Sachenwelt) aumenta em proporção direta a desvalorização do mundo dos homens (Menschenwelt). O trabalho não produz somente mercadorias; ele produz a si mesmo e ao trabalhador como uma mercadoria, e isto na medida em que produz, de fato, mercadorias em geral." (MARX, 2010, p. 80).

Na citação acima, verificamos a partir da constatação de Marx que o trabalhador, na sociedade capitalista, se torna uma mercadoria tão mais barata quanto mais mercadorias ele cria, ou seja, quanto mais riqueza (uma enorme coleção de mercadorias) o trabalhador produz, mais pobre e miserável ele se torna. O mundo das coisas (mercadorias) possui mais importância do que o mundo dos homens. Nesse processo, o trabalhador produz a mercadoria ao mesmo tempo em que produz a si mesmo, e ao trabalhador como uma mercadoria.

\section{O ESTRANHAMENTO NA ESSÊNCIA DO TRABALHO ${ }^{5}$ [TRABALHO ESTRANHADO}

5 Concordamos com Sobral na seguinte afirmação "O trabalho é apresentado de maneira dúplice nos Manuscritos: a primeira refere-se ao trabalho como uma característica específica do capitalismo, pois está determinado pela sobrevivência, pelas necessidades mais rudimentares, separado da verdadeira necessidade que é o estabelecimento de uma vida humana. O ser humano só adquire sentido, no capitalismo, como ser que trabalha por um salário. A segunda característica é a concepção de trabalho como um dos aspectos da atividade humana. O trabalho é então considerado como um elemento que deve servir ser humano, que deve ser usufruído como atividade que realiza uma parte das potencialidades humanas; para isso, é preciso que tenha sido superada a alienação, o caráter estranho do trabalho, permitindo que ele possa ser dirigido pelo esforço consciente do homem, e que a finalidade última seja a satisfação deste e não a satisfação de elementos externos, como o capital, a mercadoria e o dinheiro." (SOBRAL, 2005, p. 17).

\begin{tabular}{|l|l|l|l|l|}
\hline Q Povista Dialectus & Ano 8 & n. 14 & Janeiro - Julho 2019 & p. $278-294$ \\
\hline
\end{tabular}


Marx (2010) chega à conclusão que, na sociedade capitalista, o objeto que o trabalho produz, o seu produto, se lhe defronta como um ser estranho, como um poder independente do produtor. Que o produto do trabalho é o trabalho que se fixou num objeto, fez-se coisal, é a objetivação do trabalho. Que a efetivação do trabalho é sua objetivação. Esta efetivação do trabalho aparece, nas palavras de Marx, ao estado nacional-econômico como desefetivação do trabalhador, a objetivação como perda do objeto e servidão ao objeto, a apropriação como estranhamento ${ }^{6}$, como alienação.

Nessa forma de sociedade, o trabalhador ao produzir o objeto, o seu produto, esse mesmo objeto produzido se lhe defronta como um ser estranho, isto é, independente do trabalhador. Assim, nesse estranhamento do trabalhador com o seu produto, objeto, tem-se, justamente, o contrário da relação ideal, pois a efetivação aparece, aqui, como

6 De acordo com o tradutor dos Manuscritos econômico-filosóficos, da editorial Boitempo, Jesus Ranieri (2004), “[...] é preciso destacar a distinção sugerida, nesta tradução, entre alienação (Entäusserung) e estranhamento (Entfremdung), pois são termos que ocupam lugares distintos no sistema de Marx. É muito comum compreender-se por alienação um estado marcado pela negatividade, situação essa que só poderia ser corrigida pela oposição de um estado determinado pela positividade emancipadora, cuja dimensão seria, por sua vez, completamente compreendida a partir da supressão do estágio alienado, esse sim aglutinador tanto de Entäusserung quanto de Entfremdung. No capitalismo, os dois conceitos estariam identificados com formas de apropriação do excedente do trabalho e, consequentemente, com a desigualdade social, que aparece também nas manifestações tanto materiais quanto espirituais da vida do ser humano. Assim, a categoria alienação cumpriria satisfatoriamente o papel da categoria universal que serve de instrumento para a crítica de conjunto do sistema capitalista. Na reflexão desenvolvida por Marx não é tão evidente, no entanto, que esse pressuposto seja levado às suas últimas consequências, pois os referidos conceitos aparecem com conteúdos distintos, e a vinculação entre eles, geralmente sempre presente, não garante que sejam sinônimos. E é muito menos evidente ainda que sejam pensados somente para a análise do sistema capitalista. Entäusserung significa remeter para fora, extrusar, passar de um estado a outro qualitativamente distinto. Significa, igualmente, despojamento, realização de uma ação de transferência, carregando consigo, portanto, o sentido da exteriorização (que, no texto ora traduzido, é uma alternativa amplamente incorporada, uma vez que sintetiza o movimento de transposição de um estágio a outro de esferas de existência), momento de objetivação humana no trabalho, por meio de um produto resultante de sua criação. Entfremdung, ao contrário, é objeção socioeconômica à realização humana, na medida em que veio, historicamente, determinar o conteúdo do conjunto das exteriorizações - ou seja, o próprio conjunto de nossa socialidade - através da apropriação do trabalho, assim como da determinação dessa apropriação pelo advento da propriedade privada. Ao que tudo indica, a unidade Entäusserung - Entfremdung diz respeito à determinação do poder do estranhamento sobre o conjunto das alienações (ou exteriorizações) humanas, o que, em Marx, é possível perceber pela relação de concentricidade entre as duas categorias: invariavelmente as exteriorizações (Entäusserungen) aparecem no interior do estranhamento, ainda que sejam inelimináveis da existência social fundada no trabalho humano." (MARX, Karl. Manuscritos econômico-filosóficos; tradução, apresentação e notas Jesus Ranieri. [4a reimpr.] - São Paulo: Boitempo, 2010).

\begin{tabular}{|l|l|l|l|l|}
\hline Govista Dialectus & Ano 8 & n. 14 & Janeiro - Julho 2019 & p. $278-294$ \\
\hline
\end{tabular}


desefetivação do trabalhador, a objetivação como a perda e servidão ao objeto, a apropriação como estranhamento.

Marx, então, percebe que esta inversão se apresenta como algo natural para a economia nacional e que a servidão do trabalhador ao objeto, produto do trabalho, tem consequências nefastas para a realidade concreta e material. Pois, no modo capitalista de produção ${ }^{7}$,

\begin{abstract}
A efetivação do trabalho tanto aparece como desefetivação que o trabalhador é desefetivado até morrer de fome. A objetivação tanto aparece como perda do objeto que o trabalhador é despojado dos objetos mais necessários não somente à vida, mas também dos objetos do trabalho. Sim, o trabalho mesmo se torna um objeto, do qual o trabalhador só pode se apossar com os maiores esforços e com as mais extraordinárias interrupções. A apropriação do objeto tanto aparece como estranhamento (Entfremdung) que, quanto mais objetos o trabalhador produz, tanto menos pode possuir e tanto mais fica sob o domínio do seu produto, do capital. (MARX, 2010, p. 80-81).
\end{abstract}

Logo, com base nesta exposição, percebe-se que o trabalhador, conforme afirma Marx, desce cada vez mais a condição da mais miserável mercadoria. O mundo das coisas (objetos produzidos pelo trabalho humano) passa a ser valorizado em detrimento do mundo dos homens. O trabalhador torna-se cada vez mais pobre numa relação inversa a sua grandeza e potência no processo de produção. A mercadoria, ao assumir "vida própria" passa a controlar o mundo dos vivos. O operário produz o objeto, porém, o objeto já não está em seu poder de usufruto, pois esse objeto não pertence a ele e sim a outro, ou seja, ao burguês, ao dono da fábrica, aos capitalistas.

Ainda, de acordo com a citação acima, o próprio trabalho, segundo assevera Marx, se torna um objeto e que o trabalhador para se apossar dele deve realizar os maiores esforços. Assim, Marx afirma (2010) que quanto mais o trabalhador se desgasta trabalhando, tanto mais poderoso se torna o mundo objetivo, alheio que ele cria diante de si, tanto mais pobre se torna ele mesmo, seu mundo interior, e tanto menos pertence a si

7 Na produção capitalista o homem é pura força de trabalho, qualitativamente indiferenciável do restante dos meios e produção: já não é identificável pela forma de seu trabalho. O produto do trabalho separase do trabalhador, converte-se em objeto alheio, torna-se estranho a ele. No âmbito da propriedade privada produz-se o fenômeno geral do estranhamento, pelo qual as forças e os produtos se subtraem ao controle e ao poder dos indivíduos, transforma-se em forças contrapostas aos homens. O trabalho, portanto, configura-se ontologicamente de forma estranhada; [...]. (CHAGAS, 1994, p. 26).

\begin{tabular}{|l|l|l|l|l|}
\hline Govista Dialectus & Ano 8 & n. 14 & Janeiro - Julho 2019 & p. $278-294$ \\
\hline
\end{tabular}


próprio. É do mesmo modo na religião. Quanto mais o homem põe em Deus, tanto menos ele retém em si mesmo.

Diz Marx:

[...] A exteriorização (Entausserung) do trabalhador em seu produto tem o significado não somente de que seu trabalho se torna um objeto, uma existência externa (äussern), mas, bem além disso, [que se torna uma existência] que existe fora dele (ausser ihm), independente dele e estranha a ele, tornando-se uma potência (Macht) autônoma diante dele, que a vida que ele concedeu ao objeto se lhe defronta hostil e estranha. (MARX, 2010, p. 81).

Entendemos, a partir do exposto acima, que durante a exteriorização (do trabalhador em seu produto) o trabalho do trabalhador se torna objeto, uma existência externa, e que existe fora dele, isto é, existe independente dele e estranha a ele. Esse objeto, fruto do trabalho (exteriorização) do trabalhador aparece agora como uma potência autônoma, estranha e hostil diante de seu criador, a ponto de "ganhar vida própria”.

Ao examinar mais de perto a objetivação, a produção do trabalhador, e nela o estranhamento, a perda do objeto, a perda do seu produto, Marx afirma (2010) que o trabalhador nada pode criar sem a natureza, sem o mundo exterior sensível. Pois, esta última é a matéria na qual o seu trabalho se efetiva, na qual o trabalho é ativo, porque é a partir da qual e por meio da qual que o trabalho produz.

Ainda, de acordo com Marx,

\begin{abstract}
Quanto mais, portanto, o trabalhador se apropria do mundo externo, da natureza sensível, por meio do seu trabalho, tanto mais ele se priva dos meios de vida segundo um duplo sentido: primeiro, que sempre mais o mundo exterior sensível deixa de ser um objeto pertencente ao seu trabalho, um meio de vida do seu trabalho; segundo, que o [mundo exterior sensível] cessa, cada vez mais, de ser meio de vida no sentido imediato, meio para a subsistência física do trabalhador. (MARX, 2010, p. 81).
\end{abstract}

Portanto, segundo esse duplo sentido, Marx assevera que "o trabalhador se torna, portanto, um servo do seu objeto”. (MARX, 2010, p. 81). No primeiro momento, porque ele recebe um objeto do trabalho, ou seja, recebe trabalho. No segundo momento, porque recebe meios de subsistência. Portanto, para que possa existir, em primeiro lugar, como trabalhador e, em segundo lugar, como sujeito físico.

Assim, Marx (2010) acredita e afirma que o auge dessa servidão é que somente como trabalhador ele pode se manter como sujeito físico e apenas como sujeito

\begin{tabular}{|l|l|l|l|l|}
\hline Govista Dialectus & Ano 8 & n. 14 & Janeiro - Julho 2019 & p. $278-294$ \\
\hline
\end{tabular}


físico ele é trabalhador. Nessa forma de sociedade, a condição para a garantia da vida do homem (trabalhador) passa a ser o trabalho. Logo, se ele trabalha vive e se vive trabalha.

Nessa forma de organização social, fundamentada no trabalho (estranhado),

\begin{abstract}
O estranhamento do trabalhador em seu objeto se expressa, pelas leis nacionaleconômica, em que quanto mais o trabalhador produz, menos tem para consumir; que quanto mais valores cria, mais sem-valor e indigno ele se torna; quanto mais bem formado o seu produto, tanto mais deformado ele fica; quanto mais civilizado seu objeto, mais bárbaro o trabalhador; que quanto mais poderoso o trabalho, mais impotente o trabalhador se torna; quanto mais rico de espírito, mais pobre de espírito e servo da natureza se torna o trabalhador. (MARX, 2010, p. 82).
\end{abstract}

Verifica-se que, o trabalhador, nessa forma de sociedade, participa diretamente do processo de produção da riqueza material, porém no tocante a distribuição dessa riqueza, ele participa de forma unilateral, pois ao trabalhador só lhe é dado àquilo que lhe assegura sua existência como trabalhador e servo do capital. Uma forma de sociabilidade desigual, violenta e nociva ao desenvolvimento do ser humano. Tal forma de sociabilidade garante a desigualdade intensa e profunda entre os homens, pois sua estrutura permite, inevitavelmente, a perpetuação das contradições sociais, em especial, a existência das classes antagônicas, a saber, os burgueses (que se deleitam com a posse da riqueza produzida a partir do trabalho da maioria) e os proletários (que nada possuem e vivem na miséria material e espiritual).

Por que, então, a economia nacional oculta o estranhamento na essência do trabalho? Nas palavras de Marx, "a economia nacional oculta o estranhamento na essência do trabalho porque não considera a relação imediata entre o trabalhador (o trabalho) e a produção”. (MARX, 2010, p. 82).

Marx (2010), sem expressar dúvida, afirma que nessa sociedade do trabalho (sociedade capitalista), o trabalho produz maravilhas para os ricos, mas produz privação para o trabalhador. Produz palácios, mas cavernas para o trabalhador. Produz beleza, mas deformação para o trabalhador. Substitui o trabalho por máquinas, porém lança uma parte dos trabalhadores de volta ao trabalho bárbaro e faz da outra parte máquinas. Produz espírito, mas imbecilidade para o trabalhador.

Mais uma vez, Marx salienta a contradição existente entre o que o trabalhador produz e o que de fato o trabalhador recebe. Que a riqueza da sociedade produzida pelo trabalhador se contrapõe a forma de vida miserável do trabalhador nesta relação.

\begin{tabular}{|l|l|l|l|l|}
\hline Govista Dialectus & Ano 8 & n. 14 & Janeiro - Julho 2019 & p. $278-294$ \\
\hline
\end{tabular}


É importante perceber que o estranhamento, examinado até aqui, por Marx, a exteriorização do trabalhador apresenta-se, sob apenas um de seus aspectos, a saber: a relação do trabalhador com os produtos de seu trabalho, porém, de acordo com Marx, o estranhamento não se mostra somente no resultado (no produto final), mas também, e principalmente, no ato da produção, dentro da própria atividade produtiva. Pergunta Marx, "Como poderia o trabalhador defrontar-se alheio (fremd) ao produto da sua atividade se no ato mesmo da produção ele não se estranhasse a si mesmo?" (MARX, 2010, p. 82). A título de resposta, o próprio Marx argumenta que,

[...] O produto, é sim, somente o resumo (resumé) da atividade, da produção. Se, portanto, o produto do trabalho é a exteriorização, então a produção mesma tem de ser a exteriorização ativa, a exteriorização da atividade, a atividade da exteriorização. No estranhamento do objeto do trabalho resume-se somente o estranhamento, a exteriorização na atividade do trabalho mesmo. (MARX, 2010, p. 82).

Marx continua em busca de compreender o processo do estranhamento e lança, agora, pela segunda vez, mais uma pergunta, "Em que consiste, então, a exteriorização (Entäusserung) do trabalho?” (MARX, 2010, p. 82). E como resposta apresenta:

Primeiro, que o trabalho é externo (äusserlich) ao trabalhador, isto é, não
pertence ao seu ser, que ele não se afirma, portanto, em seu trabalho, mas nega-
se nele, que não se sente bem, mas infeliz, que não desenvolve nenhuma
energia fisica e espiritual livre, mas mortifica sua physis e arruína o seu
espírito. O trabalhador só se sente, por conseguinte e em primeiro lugar, junto
a si [quando] fora do trabalho e fora de si [quando] no trabalho. Está em casa
quando não trabalha e, quando trabalha, não está em casa. O seu trabalho não
é, portanto, voluntário, mas forçado, trabalho obrigatório. O trabalho não é,
por isso, a satisfação de uma carência, mas somente um meio para satisfazer
necessidades fora dele. Sua estranheza (Fremdheit) evidencia-se aqui [de
forma] tão pura que, tão logo inexista coerção física ou outra qualquer, foge-
se do trabalho como de uma peste. O trabalho externo, o trabalho no qual o
homem se exterioriza, é um trabalho de autossacrificio, de mortificação.
Finalmente, a externalidade (Ausserlichkeit) do trabalho aparece para o
trabalhador como se [o trabalho] não fosse seu próprio, mas de um outro, como
se [o trabalho] não lhe pertencesse, como se ele no trabalho não pertencesse a
si mesmo, mas a um outro. Assim como na religião a autoatividade da fantasia
humana, do cérebro e do coração humanos, atua independentemente do
indivíduo e sobre ele, isto é, como uma atividade estranha, divina ou diabólica,
assim também a atividade do trabalhador não é a sua autoatividade. Ela
pertence a outro, é a perda de si mesmo.” (MARX, 2010, p. 82-83).

O trabalhador não se afirma no seu trabalho, uma vez que o trabalho se apresenta como algo externo e independente ao trabalhador, isto é, não pertence ao

\begin{tabular}{|l|l|l|l|l|}
\hline Q Povista Dialectus & Ano 8 & n. 14 & Janeiro - Julho 2019 & p. 278 - 294 \\
\hline
\end{tabular}


trabalhador como atividade integrada ao seu ser. O que deveria ser afirmação torna-se, então, negação, o trabalhador não se reconhece nessa forma de trabalho. Assim, na primeira oportunidade que tem para fugir do trabalho, tão logo inexista coerção física ou qualquer outra, afirma Marx, "foge-se do trabalho como de uma peste". (MARX, 2010, p.83). O ato do estranhamento sobre o trabalho faz também com que o trabalhador não se reconheça no produto do trabalho. Este produto atua como um objeto estranho, poderoso e independente sobre o trabalhador. O próprio trabalho externo, no qual o homem se exterioriza, passa a ser, nas palavras de Marx, um "trabalho de autosacrifício, de mortificação”. (MARX, 2010, p. 83). O próprio trabalho aparece para o trabalhador como se não lhe pertencesse, mas a outro.

Após a detalhada exposição do estranhamento do trabalhador e de sua produção, no contexto da sociedade capitalista, Marx pergunta: "Se o produto do trabalho me é estranho, [se ele] defronta-se comigo como poder estranho, a quem pertence então?” (MARX, 2010, p.86); “Se minha própria atividade não me pertence, é uma atividade estranha, forçada, a quem ela pertence, então?” (MARX, 2010, p.86).

Como resposta, Marx argumenta: “A outro ser que não eu.” (MARX, 2010, p. 86). E continua a perguntar, “Quem é este ser?” (MARX, 2010, p. 86); “Os deuses?” (MARX, 2010, p. 86). Na sequência, responde o pensador materialista:

[...] Evidentemente nas primeiras épocas a produção principal, como por exemplo a construção de templos etc., no Egito, na Índia, México, aparece tanto a serviço dos deuses, como também o produto pertence a eles. Sozinhos, porém, os deuses nunca foram os senhores do trabalho. Tampouco a natureza. E que contradição seria também se o homem, quanto mais subjugasse a natureza pelo seu trabalho, quanto mais os prodígios dos deuses se tornassem obsoletos mediante os prodígios da indústria, tivesse de renunciar à alegria na produção e à fruição do produto por amor a esses poderes. (MARX, 2010, p. 86).

Marx (2010) conclui, então, a título de resposta e chega a seguinte afirmação, a saber, que esse ser estranho ao qual pertence o trabalho e o produto do trabalho, para o qual o trabalho está ao seu serviço e para a fruição do qual está o produto do trabalho, só pode ser o homem mesmo. Portanto, se o produto do trabalho não pertence ao trabalhador e se o resultado do seu trabalho não é para seu usufruto, então, pode-se concluir que, só pode pertencer a outro homem, que não é um trabalhador. Diz Marx, "Se sua atividade lhe é martírio, então ela tem de ser fruição para um outro e alegria de viver 
para um outro. Não os deuses, não a natureza, apenas o homem mesmo pode ser este poder estranho sobre o homem". (MARX, 2010, p. 86).

Marx (2010) afirma que, como resultado do trabalho estranhado, o homem (o trabalhador) só se sente como um ser livre e ativo em suas funções animais, comer, beber e procriar, quando muito ainda habitação, adornos etc., e em suas funções humanas só se sente como animal. O animal se torna humano, e o humano, animal, ou seja, uma inversão nociva capaz também de estranhar o homem do seu próprio caráter genérico.

\section{A RELAÇÃO ENTRE O TRABALHO-EDUCAÇÃO NO PENSAMENTO DE MARX}

A teoria de Marx sobre o estranhamento na essência do trabalho [trabalho estranhado] foi apresentada, em detalhes, na primeira parte deste artigo (2 O ESTRANHAMENTO NA ESSÊNCIA DO TRABALHO [TRABALHO ESTRANHADO], p. 4). Portanto, aqui, nesta seção, explicitaremos, então, a relação entre o trabalho estranhado e educação no pensamento de Marx.

$\mathrm{Na}$ presente pesquisa, defendemos que Marx expõe, inicialmente, sua teoria sobre o estranhamento na essência do trabalho nos Manuscritos econômico-filosóficos (1844), especificamente, no final do primeiro manuscrito intitulado [Trabalho estranhado e propriedade privada], após uma longa exposição das categorias econômicas da economia nacional.

Na obra, Marx apresenta, em caráter revelador, as consequências nefastas do estranhamento na essência do trabalho para desenvolvimento pleno das capacidades humanas. Pois, para Marx, na sociedade capitalista, o trabalhador baixa a condição da mais miserável mercadoria e o seu preço está totalmente relacionado aos custos de sua produção. A atividade vital humana aparece no capitalismo apenas sob a forma de emprego. O homem passa a viver em função de um mero trabalho (emprego) de tal forma que sua vida depende totalmente deste último.

Neste escrito, Marx examina, inicialmente, o estranhamento da atividade humana prática, o trabalho sob dois aspectos, a saber: 1) A relação do trabalhador com o produto do trabalho como objeto estranho e poderoso sobre ele [trabalhador]. Para Marx, esta relação é ao mesmo tempo a relação com o mundo exterior sensível, ou seja, com os objetos da natureza como um mundo alheio [não pertencente ao trabalhador] que se lhe defronta hostilmente. 2) A relação do trabalho com ato da produção no interior do

\begin{tabular}{|l|l|l|l|l|}
\hline Govista Dialectus & Ano 8 & n. 14 & Janeiro - Julho 2019 & p. $278-294$ \\
\hline
\end{tabular}


trabalho. Para Marx, esta relação é a relação do trabalhador com a sua própria atividade como uma atividade estranha, isto é, não pertencente ao trabalhador. Aqui, a atividade se manifesta como miséria, a força como impotência, a procriação como castração. Diz Marx: "A energia espiritual e física própria do trabalhador, a sua vida pessoal - "pois o que é vida senão atividade" - como uma atividade voltada contra ele mesmo, independente dele, não pertencente a ele. [...].” (MARX, 2010, p. 83).

Após examinar o estranhamento da atividade humana prática sob esses dois aspectos, Marx afirma, ainda que, o trabalho estranhado faz, por conseguinte: 3 ) do ser genérico do homem, tanto da natureza quanto da faculdade genérica espiritual dele, um ser estranho a ele, um meio da sua existência individual. Pois, segundo Marx, o trabalho estranhado estranha do homem o próprio corpo, assim como estranha do homem a natureza fora dele, tal como a sua essência espiritual, a sua essência humana. 4) uma consequência imediata de o homem estar estranhado do produto do seu trabalho, de sua própria atividade vital e de seu ser genérico é o estranhamento do homem pelo próprio homem. Pois, Marx assevera que quando o homem está frente a si mesmo, defronta-se com ele o outro homem. Assim, diz Marx: "O que é produto da relação do homem com o seu trabalho, produto de seu trabalho e consigo mesmo, vale como relação do homem com outro homem, como o trabalho e o objeto do trabalho de outro homem." (MARX, 2010, p. 86).

Marx desenvolve, então, sua concepção sobre a categoria trabalho diferente da concepção desenvolvida pela economia nacional. Pois, entendemos que, para Marx, o trabalho (atividade humana prática) deve proporcionar uma relação de reconhecimento entre o trabalhador e o objeto por ele produzido, ou seja, diferente da relação produzida pelo trabalho estranhado de tal forma que o trabalhador tenha domínio sobre esta relação. Neste domínio, o trabalhador deve além de se reconhecer no objeto, ao mesmo tempo, também dominá-lo e não ser por ele dominado. Assim, deduzimos e afirmamos que a relação do homem com os objetos exteriores a ele se daria numa relação de reconhecimento e não de estranhamento. Para Marx, o trabalho não deve se apresentar ao homem como uma atividade estranha, porque, entendemos que por meio do trabalho o homem se libertou das condições naturais (impostas pela natureza). A atividade humana prática (trabalho) deve se apresentar como uma alienação (positiva) primordial capaz de desenvolver o conjunto das objetivações humanas, ou melhor, a atividade humana prática como riqueza humana, a força como potência, a procriação como procriação. Portanto, o 
trabalho deve estar a serviço do desenvolvimento pleno das capacidades humanas, pertencente totalmente ao homem como uma atividade humana de autodesenvolvimento e autoformação.

Entendemos que Marx a partir do trabalho estranhado se depara com o estranhamento do homem pelo próprio homem. No capitalismo, forma histórica de organização social, o estranhamento estudado por Marx se apresenta na vida prática, real e concreta dos homens e suas consequências são apresentadas em tom de denúncia nos Manuscritos econômico-filosóficos (1844).

Para Marx, a atividade humana prática é responsável pelo autoreconhecimento e auto-desenvolvimento humano. Deve unir o homem ao seu próprio corpo, a natureza fora dele e sua essência humana.

Portanto, defendemos que, ao analisar o estranhamento na essência do trabalho, Marx não realiza uma análise abstrata, separada das relações reais. Tal análise, nesse sentido, possui uma articulação com a vida real, concreta e material produzida pelos próprios homens, ou seja, a mesma está diretamente articulada com o modo de produção, com a vida social, histórica, política e econômica.

Marx não parte de um estado primitivo imaginário para compreensão da realidade social, pois, para o pensador alemão, um "tal estado primitivo nada explica". (MARX, 2010, p.80).

Marx parte da realidade concreta e material dos homens e percebe que nessa forma de sociedade "o trabalhador se torna tanto mais pobre quanto mais riqueza produz" (MARX, 2010, p. 80). ; “O trabalhador se torna uma mercadoria tão mais barata quanto mais mercadorias cria" (MARX, 2010, p.80). ; uma forma de sociedade que supervaloriza o mundo das mercadorias e desvaloriza o mundo dos homens. Pois, na sociedade capitalista, conforme assevera Marx, "O trabalho não produz somente mercadorias; ele produz a si mesmo e ao trabalhador como uma mercadoria, e isto na medida em que produz, de fato, mercadorias em geral." (MARX, 2010, p. 80).

Portanto, diz Marx:

Este fato nada mais exprime, senão: o objeto (Gegenstand) que o trabalho produz, o seu produto, se lhe defronta como um ser estranho, como um poder independente do produtor. O produto do trabalho é o trabalho que se fixou num objeto, fez-se coisal (sachlich), é a objetivação (Vergegenständlichung) do trabalho. A efetivação (Verwirklichung) do trabalho é a sua objetivação. Esta efetivação do trabalho aparece ao estado nacional-econômico como desefetivação (Entwirklichung) do trabalhador, a objetivação como perda do 
objeto e servidão ao objeto, a apropriação como estranhamento (Entfremdung), como alienação (Entäusserung).” (MARX, 2010, p. 80).

Marx revela, na passagem acima, o estranhamento na essência do trabalho e, na ocasião, esclarece como ocorre o processo de empobrecimento da classe trabalhadora por meio do trabalho nas condições impostas pelo capitalismo. Ao revelar que a efetivação do trabalho aparece, no capitalismo, como desefetivação, a objetivação como perda do objeto e, ao mesmo tempo, servidão ao objeto, a apropriação como estranhamento, como alienação, entendemos que o próprio homem cria o estranhamento na essência do trabalho. Assim, perguntamos, então, qual a relação entre o estranhamento na essência do trabalho [trabalho estranhado] e educação no pensamento de Marx?

Defendemos que se encontra implícito no pensamento de Marx, em especial, neste manuscrito (Trabalho estranhado e propriedade privada), a relação entre o trabalho estranhado com a sua concepção de educação, pois, ao revelar que o trabalho nas condições impostas pela sociedade capitalista impede o desenvolvimento pleno das capacidades humanas, Marx fundamenta, assim, a relação necessária entre o trabalho e a educação para o desenvolvimento pleno das capacidades humanas, porém, diferente da lógica do capital. Vejamos, então, melhor este argumento.

Marx afirma que na sociedade capitalista,

A efetivação do trabalho tanto aparece como desefetivação que o trabalhador é desefetivado até morrer de fome. A objetivação tanto aparece como perda do objeto que o trabalhador é despojado dos objetos mais necessários não somente a vida, mas também dos objetos do trabalho. [...]. (MARX, 2010, p. 80).

Pois, para Marx, o que deveria ser a efetivação do trabalhador, torna-se, então, desefetivação, uma vez que o trabalhador não se reconhece no produto do seu próprio trabalho. Assim, na sociedade do capital, o trabalho (estranhado) torna-se um empecilho ao autodesenvolvimento humano. Não desenvolve o homem, muito pelo contrário, atrofia e se torna algo nocivo e pernicioso para o trabalhador, ou melhor, o próprio trabalho se torna algo agressivo ao trabalhador.

No capitalismo, o trabalhador não possui liberdade para produzir. Este produz sob as determinações de outro homem, estranho a ele. O trabalhador não possui os objetos mais necessários para a realização do trabalho, pois estes objetos foram historicamente expropriados. Assim, entendemos que Marx ao defender a tese da união da educação com a produção material, em meados de 1848, no Manifesto Comunista (1848), percebe-se

\begin{tabular}{|l|l|l|l|l|}
\hline Govista Dialectus & Ano 8 & n. 14 & Janeiro - Julho 2019 & p. $278-294$ \\
\hline
\end{tabular}


que, tal união é necessária para a retomada consciente e responsável do homem sobre o trabalho, isto é, que tal união deveria contribuir no processo de desalienação do homem em relação, inicialmente, ao processo de produção, para deste ponto, gradualmente, o homem retornar ao próprio homem, isto é, ao homem social.

Embora não tenha dedicado um escrito ou até mesmo um manuscrito sobre o tema da educação, porém, entendemos que tal temática não passou despercebida na produção teórica de Marx durante a elaboração dos Manuscritos econômico-filosóficos (1844) e de outras obras da juventude e da maturidade. Pois, diante da importância dos Manuscritos de 1844, e, principalmente, do pensamento filosófico de Marx, é possível delinear princípios para a sustentação de uma educação de caráter humanístico para este pensador alemão.

Portanto, diante da teoria do estranhamento, encontramos, em Marx, o princípio primordial para fundamentar a concepção de educação, a saber; a concepção filosófica humanista presente, principalmente, nos Manuscritos econômico-filosóficos (1844). Pois, tal concepção é a planta fundamental para a construção de uma nova sociedade que tem como ponto de partida a crítica consciente das contradições reais do capitalismo $^{8}$ e a atividade prática revolucionária para a transformação da realidade existente.

Nesse sentido, percebe-se que tal transformação parte do existente e não do idealizado, ou seja, parte de uma intervenção responsável e consciente dos homens sobre a realidade material para uma transformação radical das condições dadas anteriormente que sustentam a sociedade do capital, pois, para Marx, a sociedade capitalista é uma sociedade, assim, como outras formas de organizações sociais, constituída e organizada social e historicamente, ou melhor, a forma de organização social na sociedade capitalista é uma construção humana e assim como foi construída pode também ser destruída pelo próprio homem.

8 “.... Nos seus poderosos estudos, artigos e discursos, Marx mostra concretamente qual é a situação material dos homens no capitalismo em desenvolvimento e o que será no futuro. Com séria exatidão, que expressa o rigor dos juízos científicos e morais, Marx expõe as desumanas condições de vida a que o capitalismo submete os seus escravos. Também mostra como o egoísmo da propriedade e o meio da catástrofe condicionam a classe dominante e exploradora. Estas questões históricas morais e humanitárias na caracterização das relações existentes aparecem muito claras nas análises de Marx. Questões que se referem à situação dos homens na época capitalista e que possuem uma grande importância para a pedagogia." (SUCHODOLSKI, 1976, p.121).

\begin{tabular}{|l|l|l|l|l|}
\hline Q Rovista Dialectus & Ano 8 & n. 14 & Janeiro - Julho 2019 & p. 278 - 294 \\
\hline
\end{tabular}


Ao criticar a forma como o trabalho se manifesta no capitalismo, Marx proclama: "Sim, o trabalho mesmo se torna um objeto, do qual o trabalhador só pode se apossar com os maiores esforços e com as mais extraordinárias interrupções”. (MARX, 2010, p. 81). Marx defende, então, a construção de uma sociedade de valorização do homem. Tal sociedade deve ser construída pelo próprio homem liberto do estranhamento. Assim, o trabalho, socialmente constituído, deve proporcionar ao trabalhador toda a riqueza produzida em poder e extensão. Pois, para Marx, o trabalho produz a si mesmo e ao próprio homem.

Diante da fundamentação acima, a educação possui um papel relevante e uma conexão direta e necessária com o trabalho produtivo, criador de valores de uso, pois entendemos que é impossível pensar a construção de uma nova sociedade humana sem refletir sobre a socialização dos valores produzidos social e historicamente. Nesse sentido, reforçamos que o trabalho deve ser compreendido também como uma atividade formativa responsável pelo desenvolvimento pleno das capacidades humanas.

Neste processo formativo, a educação ${ }^{9}$ deve proporcionar ao homem (trabalhador) uma relação imediata entre o trabalho e a produção, isto é, entre o trabalhador e os objetos da produção. O homem deve desenvolver no trabalho sua energia física e espiritual de forma livre, o trabalho deve ser, então, voluntário, e não obrigatório como se apresenta no capitalismo. Assim, o trabalho, a atividade vital, deve satisfazer as carências humanas mediante sua realização. Pois, para Marx, o trabalho deve se apresentar ao homem como sua autoatividade, ou seja, sua autorealização, porque o trabalho, a "atividade consciente e livre é o caráter genérico do homem.” (MARX, 2010, p.84).

\section{Referências:}

\footnotetext{
9 “A educação dos homens constitui, pois, um importante processo da autoprodução dos homens no decurso do seu trabalho social produtivo. Mas, como ensina o materialismo histórico, este processo não decorre de modo linear. Pelo contrário, realizar-se mediante lutas e contradições. [...]”. (SUCHODOLSKI, 1976, p. 94). Ainda, de acordo com Suchodolski, “[...] A verdadeira educação deve ter como base a participação do indivíduo no movimento do progresso histórico e não apenas nas divergências ideológicas. Por isso, a teoria pedagógica deve estar isenta de qualquer posição idealista, de qualquer individualismo a propósito da ação histórica das massas.” (SUCHODOLSKI, 1976, p. 44).
}

\begin{tabular}{|l|l|l|l|l|}
\hline Q Povista Dialectus & Ano 8 & n. 14 & Janeiro - Julho 2019 & p. $278-294$ \\
\hline
\end{tabular}


AMORIM, Maria Luísa de Aguiar. Trabalho e formação humana em Marx. Fortaleza: Expressão Gráfica e Editora, 2014.

CHAGAS, Eduardo Ferreira. A natureza dúplice do trabalho em Marx: trabalho útilconcreto e trabalho abstrato. In: Outubro - Revista do Instituto de Estudos Socialistas. No 19. Campinas - São Paulo, 2011.

KONDER, Leandro. Marx - Vida e obra. São Paulo: Paz e Terra, 1999.

MANACORDA, Mario Alighiero. Marx e a pedagogia moderna. São Paulo: Cortez: 1991.

MARX, Karl. ENGELS, Friedrich. Manifesto Comunista. Organização e introdução de Osvaldo Coggiola. São Paulo: Editorial Boitempo, 2007.

MARX, Karl. Manuscritos Econômico-Filosóficos. Tradução, apresentação e notas de Jesus Ranieri. São Paulo: Boitempo Editorial, 2010.

MARX, Karl. O Capital: Crítica da Economia Política - Livro I: O processo de produção do capital. Vol. I. Tradução de Reginaldo Sant'Ana - 26 a edição. Rio de Janeiro: Civilização Brasileira, 2008.

MARX, Karl. O Capital: Crítica da Economia Política - Livro I: O processo de produção do capital. Tradução: Rubens Enderle. São Paulo: Boitempo Editorial, 2011.

Marx, Karl; ENGELS, Friedrich. Textos sobre educação e ensino. Campinas: SP: Navegando, 2011. (organizador: José Claudinei Lombardi).

MÉSZÁROS, Istvan. A educação para além do capital. [tradução Isa Tavares]. - 2. Ed.São Paulo: Boitempo, 2008.

NOGUEIRA, Maria Alice. Educação, saber, produção em Marx e Engels. $2^{\mathrm{a}}$ ed. - São Paulo: Cortez, 1993.

RANIERI, Jesus José. Alienação e estranhamento em Marx: dos Manuscritos econômico - filosóficos de 1844 à ideologia alemã / Jesus José Ranieri. Campinas, SP: [s.n.], 2000.

SOBRAL, Fábio Maia. Concepção circular de homem em Marx: um estudo a partir dos Manuscritos Econômico-Filosóficos de 1844. São Paulo: Editora Nojosa, 2005.

SUCHODOLSKI, Bogdan. Teoria Marxista da Educação. Tradução de Maria Carlota Melo. Editorial Estampa, Lisboa, 1976. 